\title{
Diversification, Risk Aversion and Expectation in a Holdout Scenario
}

\author{
Wolfgang Eggert \\ Maximilian Stephan \\ Janine Temme \\ Handirk von Ungern-Sternberg
}

\author{
CESIFO WORKING PAPER NO. 5527 \\ CATEgORY 7: Monetary POLICY AND InTERnational FinANCE \\ SEPTEMBER 2015
}

An electronic version of the paper may be downloaded

- from the SSRN website: Www.SSRN.com

- from the RePEc website: Www.RePEc.org

- from the CESifo website: www.CESifo-group.org/wp 


\title{
Diversification, Risk Aversion and Expectation in a Holdout Scenario
}

\begin{abstract}
We argue a holdout is not a destructive investor behaviour but a rational investment decision. This investment decision is characterised by the mean-variance approach. We investigate intercreditor conflict by diverse portfolio structure. We demonstrate that at some point during the Greek (2012) and Argentine (2005) debt restructuring programs it was reasonable for the investor to hold out. This model shows that the investment decision is based on the portfolio structure, risk aversion and expected payment of the debtor, so there is no free-rider behaviour. On the contrary, the investor harms herself when playing a destructive or uncooperative strategy.

JEL-Code: G180, H500, H630.
\end{abstract}

Keywords: sovereign debt, holdout, mean-variance approach, collective action clause.

\author{
Wolfgang Eggert \\ Department of Economics \\ Albert-Ludwigs-University Freiburg \\ Freiburg / Germany \\ wolfgang.eggert@vwl.uni-freiburg.de \\ Janine Temme \\ Department of Economics \\ Albert-Ludwigs-University Freiburg \\ Freiburg / Germany
}

\author{
Maximilian Stephan \\ Department of Economics \\ Albert-Ludwigs-University Freiburg \\ Freiburg / Germany \\ Maximilian.Stephan@vwl.uni-freiburg.de \\ Handirk von Ungern-Sternberg \\ Department of Economics \\ Albert-Ludwigs-University Freiburg \\ Freiburg / Germany \\ handirk.von.ungern@vwl.uni-freiburg.de
}

Version 2015/10/09 


\section{Introduction}

In the event of debt restructuring of an insolvent state, there are a number of coordination problems both between the debtor and the creditor and among creditors. This paper focusses on creditor coordination problems during the restructuring process. Holdout investors press for higher or full debt settlement by the debtor. This behaviour may result in a delay or even a failure of the restructuring which is why Daniels and Ramirez (2007) cautioned against the consequences of a holdout. ${ }^{1}$ We examine the circumstances under which a restructuring offer should be accepted and when is it better to hold out? This gave rise to the question which factors determine an investor's decision to give or deny her consent. Based on the mean-variance approach we will demonstrate that a decision to agree or to hold out is rather an investment decision than a free-rider problem as is often argued in the literature. In this context, consent will depend on the number of assets invested. The more assets an investor holds in her portfolio, the more she is diversified and the more likely she will agree to the restructuring. In this case, the depreciation is low and the investing opportunity costs of a holdout would be greater. If the expected possible payment increases, the holdout behaviour increases, because in the same time the investors profit increases. The higher the costs of a restructuring, the more likely the investor will agree to it, as profits from a holdout minus its costs need to exceed the benefit of an agreement.

Section 2 provides a review of the literature published on this issue. Section 3 describes the model. In section 4, we admit uncertainty about expected yields and then analyse how this will affect the decision. Section 5 discusses consequences of a collective action clause (CAC) before looking at the model in the context of the restructuring of Greek and Argentine sovereign debt in Section 6.

\section{Literature Review}

Some economists view the holdout problem as a type of free-rider problem which would characterise a holdout as the dominant strategy (Helleiner 2008, Coffe and Klein 1991, Tamura 2002 and Daniels and Ramirez 2007). Consequently, the best strategy for a creditor would be to refuse restructuring and insist on full repayment of the debt if all other creditors accept. Where other creditors pursue the same strategy, it is equally beneficial to refuse the

\footnotetext{
${ }^{1}$ Holdout behaviour was for instance observed during the Argentine crisis by NML Capital and Aurelius.
} 
restructuring. The other creditors will thus not benefit from their decline. This is a problem since there is an incentive for all creditors to refuse to grant their consent to the restructuring (Roubini 2002 and Daniels and Ramirez 2007). This behaviour is described by Helleiner (2008) as free-riding. Investors hold out expecting better terms and reject the restructuring. According to Coffe and Klein (1991), Tamura (2002) and Daniels and Ramirez (2007) a classic prisoner's dilemma is created. This renegotiations between the debtor and creditors is more time consuming and costly for all parties involved. Pitchford and Wright (2011) explain a holdout with strategic behaviour. The coordination problem between creditors is illustrated by the level of consent in restructuring negotiations. Thus, the level of consent in Argentina in 2005 was 76\%. In the 2010 Greek restructuring, $85.8 \%$ of investors gave their consent. A disorderly insolvency would be the worst case scenario, as was the case in Argentina (2005).

Nonetheless, some investors have an incentive to press for full debt settlement by taking legal action. So did hedge funds against Argentina in a US court and obtained a ruling entitling them to a USD 1.33 bn payment. An effective restructuring mechanism will have to avoid such a "grab race" or "rush to the courthouse" (Eichengreen and Porter 1995). This may lead to serious problems if the debtor's assets are accessed (Roubini 2002). A rush to the courthouse will result in a number of inefficiencies as such a procedure is costly and time consuming for creditors and debtors alike. This becomes evident in the case of Argentina: the court case between Argentina and the holdout creditors of NML Capital and Aurelius drags on to this day. Moreover, the US Sovereign Immunities Act of 1976 establishes limitations for court action against sovereign states in the event of insolvency. ${ }^{2}$ The group of holdout creditors is heterogeneous: it comprises speculators betting for higher profits on the one hand and institutional investors who claim special or different treatment during the restructuring on the other hand. Larger banks usually have an interest in continued relationships with the creditor and are thus likely to agree while small investors demand a more moderate restructuring and take legal action (Miller and Thomas 2007). Furthermore, it is generally very difficult to access assets of a country in the middle of a restructuring procedure. ${ }^{3}$

The limited course of action against an insolvent state combined with the empirical levels of consent conflict with the free-rider argument. If a free-rider problem exists in holdouts, levels of consent would be much lower than those observed in reality. The levels of consent during

\footnotetext{
${ }^{2}$ This puts the USA in a difficult position as a law suit before a US court will implicate the USA in the conflict between creditors and debtors.

${ }^{3}$ Domestic assets as well as possessions of diplomatic agencies are always exempt from creditors' access.
} 
the restructuring of Pakistan, Ukraine, Ecuador and Russia amounted to $96 \%$ to $99 \%$. Creditors give their consent for two reasons: First, they are concerned about insolvency and second the restructured bond is more liquid (Eichengreen 2003). This rationale is contradictory to the idea of free-rider behaviour. Investors thus have reasons not to hold out. Some economists consider a CAC to be the solution to the problem (Eichengreen and Mody 2004, Eichengreen and Porter 1995 as well as Haldane et al 2005). Haldane et al (2005) demonstrate that the CAC provides a solution to the problem of inefficiency resulting from free-rider behaviour.

Roubini (2002) argues that the free-rider problem is not essential in a sovereign debt restructuring. He discusses ways to avoid "rude" investor behaviour without making use of a CAC. Roubini gives a number of reasons for which the holdout problem is irrelevant in practice. One of these reasons is the fact that there is a restructuring offer which is accepted by many cooperative bond holders. In the process, old bonds are exchanged for new ones. The cases of Ecuador, Pakistan, Russia and the Ukraine illustrated that this was accepted by approx. $99 \%$ of the investors. In addition, non-financial conditions may be modified in order to compensate for the advantages of a holdout. The debtor may provide collateral or offer an upgrade of seniority. In addition, it is mainly financial intermediaries who are the countries' largest creditors and maintain further business relationships with the debtor which is why they will give their consent in order not to burden this relationship. Another important reason is the erroneous assumption that the holdout investor will generate a higher yield than the agreeing investor (Roubini 2002). First, it cannot be assumed that the holdout will lead to full repayment. The holdout investor may be able to yield higher returns after a potential recovery of the debtor's financial situation not, however, without time consuming, expensive and risky negotiations. Second, the majority of creditors will accept the restructuring offer if this is not below the current market value. On average, the debtors' offers exceeded market prices by about 20-30\% (Roubini 2002). This is why they are accepted by the majority of the creditors. The question therefore arises: what are the circumstances under which a restructuring offer should be accepted and when is it better to hold out? What are the parameters that influence an investor's decision?

If the holdout behaviour is indeed a free-rider problem, the dominant strategy consists in not agreeing and investors would reject the restructuring offer of the debtor. This is an investment decision, however, which involves costs for the holdout; the investor aims to maximise her benefit. She has expectations about the yield and the cost incurred due to the holdout. As the level of consent in most restructuring negotiations is between 96-99\%, these cases can be seen 
as 'herd' behaviour, which was demonstrated by Engelen and Lambsdorff (2009) in a "staghunt" game. In the coordination game between creditors and the debtor, the creditor will incur additional costs once she rejects the restructuring offer. In this model, it is risky to reject the offer since the costs, which are assumed to be fixed, will have to be borne by all rejecting participants. The fewer investors reject, the higher the costs will be. This is why a player should agree if all others agree. If the other participants disagree, they share the burden of the cost and it is thus beneficial for a player not to agree. This explains the herd behaviour of the participants, their best strategy is to follow the decisions of the other players.

Eichengreen and Porter (1995) describe that in a group of many creditors each individual creditor loses the incentive to monitor the debtor which results in herd behaviour. Calvo and Mendoza (2000) demonstrate that herd behaviour can be more advantageous than monitoring. We therefore build on the model of Calvo and Mendoza (2000) to illustrate when a holdout would be beneficial and when agreement would be more sensible. In the underlying model, an investor may invest into J different investment opportunities. In our model we consider a case in which a state cannot serve the debt and defaults. Since there is no regulatory framework for sovereign debt restructuring and we do not assume the existence of a CAC, the investor may opt for an agreement or a holdout once the debtor has presented a restructuring offer. In the event of accepting it, the investor will receive a secure payment previously negotiated. A similar negotiation game under uncertain information was modelled by Chatterjee and Samuelson (1983). Bolton and Jeanne (2009) presented the difficulties during a restructuring of different types of investments, Haldane et al (2005) referred to a strategic game based on information asymmetry. Eichengreen and Porter (1995) argue that there will only be an efficient outcome if creditors and the debtor have symmetric information. Creditors, however, are not fully informed.

If a creditor decides to hold out, repayment is uncertain and she will have to bear costs to ensure performance of the debtor's obligations. We assume that the debtor will not meet obligations in the event of a holdout and that there will not be a second round of negotiations, in other words, this is a one-shot game. The costs for ensuring complete settlement of obligations may arise from different sources. These might be information costs, litigation costs, costs for enforcement or costs which have to be borne in order to access assets of the debtor. Since the end of gunboat diplomacy at the turn of the $20^{\text {th }}$ century the issue of sovereignty has existed. Consequently, there is no right to access assets on domestic soil of the debtor. Liquidation of assets for the 
purpose of servicing debt as practised in the case of companies is thus not an option. It is our goal to identify the circumstances under which a holdout is beneficial.

\section{The model}

In a globalized financial market there are many risk averse investors as well as a large variety of bonds $\mathrm{J}(2<\mathrm{J}<\infty)$ that investors can select. We assume that there are atomized investors who hold shares as in Bolton and Jeanne (2009). ${ }^{4}$ When looking at investment decisions we apply a mean-variance approach. Portfolio investments are allocated in J-1 countries j. The characteristics of the variance and the rate of return are the same in all $\mathrm{J}-1$ countries and differ from country $i$. The rate of return regarding $J-1$ assets equals $q$ and the variance $\sigma_{j}^{2}$, respectively. These correspond to the return $\mathrm{q}$ and the variance $\sigma_{\mathrm{j}}^{2}$ of the value portfolio, which is fully diversified by weighing all countries equally. Country $i$, that is going through the process of debt restructuring, offers the secure rate of return $r_{A}$. This is true unless the investor holds out and requests a complete repayment of outstanding debt. So country $i$ has a rate of return $r$ and a variance $\sigma_{i}^{2}$. In the case of a holdout we assume an investment decision. Country i's bonds are correlated with all other J-1 country's bonds.

The share invested in the world fund is characterized by $\alpha$, the share invested in the individual portfolio by $1-\alpha$. The correlation between the world fund and an individual portfolio is given by $\theta$. In case of a repayment there are fixed costs to the amount of $K$. There are no variable costs as accrued costs are not related to the return. The risk aversion of investors is denoted by $\gamma$, we have $\gamma>0$ as investors are risk averse.

The equilibrium is defined as an overall identical investment opportunity, with $r^{*}=q$ and $\sigma_{j}^{2}=$ $\sigma_{\mathrm{i}}^{2}=\sigma^{2}$. Investors' assets are normalized to one, so that $1 / \mathrm{J}$ is the investment per selected assets. The rate of return is $\mathrm{q}$ and the variance amounts to $\sigma^{2} / \mathrm{J}$. The investor is fully diversified if all assets are selected and the risk decreases with an increasing $\mathrm{J}$. If there is a sovereign bankruptcy, there will be an offer to all creditors concerning a restructuring. Creditors can

\footnotetext{
${ }^{4}$ This assumption reflects the changes that have occurred to the creditor structure of bonds. In the period between the Second World War and the 1990s, national debt was mainly characterized by syndicated loans; however since the 1990s, states mainly issue bonds. As Rogoff and Zettelmeyer (2002) note, the private sector hardly granted credit to developing countries before the 1970s. The shift to offering bonds over syndicated loans, changed the creditor structure. One consequence of this change is that creditors have little knowledge concerning the behavior of other creditors in the event of a restructuring. The resulting simultaneous actions by creditors acting under uncertainty complicate herd behavior.
} 
accept the offer or reject and holdout. If it is accepted, the offer will ensure a safe payment and thus $\sigma_{\mathrm{i}}^{2}=0$. If the offer is rejected the creditor needs to find information and incur costs for the payment of debt. Costs are related to asset $\mathrm{i}$ whereas the other $\mathrm{J}-1$ assets are not related to costs. The expected rate of return $r$ is uncertain accompanied by a positive variance $\sigma_{i}^{2}>0$.

In the event of a debt restructuring the creditor receives an offer. She has the opportunity to accept or to reject this offer. Therefore, she calculates her payoff for both holding out and accepting. We want to investigate in which case the investor is better off to hold out and incur the costs of enforcement. For this reason, we compare the utility of investors who accept the restructuring with the expected utility of investors who reject it.

We operate with the mean-variance approach. The expected value is given by $\mu=\alpha q+$ $(1-\alpha) r$. In the first step we exclude correlation, so we have $\theta=0$. The second step allows for correlation. The variance $\sigma^{2}=\alpha^{2} \sigma_{\mathrm{W}}^{2}+(1-\alpha)^{2} \sigma_{\mathrm{i}}^{2}$ is determined by the variances of the two portfolios. The first term corresponds to the well diversified world fund and the second term corresponds to the individual portfolio. Furthermore, we assume that there is a continuum of risk averse investors $\mathrm{c}$. They differ in risk aversion, expectations about the payment in a holdout case and the structure of the portfolio.

The utility function of the investor accepting the restructuring is represented by

$$
\mathrm{U}_{\mathrm{c}}^{\mathrm{A}}=\alpha^{\mathrm{A}} \mathrm{q}+\left(1-\alpha^{\mathrm{A}}\right) \mathrm{r}_{\mathrm{A}}-\frac{\gamma}{2} \frac{\left(\alpha^{\mathrm{A}} \sigma\right)^{2}}{\mathrm{~J}-1}
$$

where index A denotes accepting the restructuring. The variable $r_{A}$ describes the investors' rate of revenue in case of approval. In our case we have $r_{A}>0$. The optimal share invested in the world fund is expressed by $\alpha^{\mathrm{A}}$. The investors' utility of agreement on rescheduling increases when there is agreement due to the rate of return in the world fund and the individual portfolio. A higher level of risk reduces utility as the investor is risk averse. Equation [1] includes only the variance of the world fund when the investor agrees on rescheduling. A higher level of risk is associated with a lower level of diversification. Therefore, we can divide the variance by the amount of invested assets. There is no uncertainty regarding payment after restructuring, so the variance of the individual portfolio is dropped out of the equation. First, the portfolio's optimal allocation is determined. The first order condition reveals

$$
\alpha^{A}=\frac{q-r_{A}}{\gamma \sigma^{2}}(J-1)
$$


The share invested in the world fund increases with the amount of investment opportunities. As all variables are larger than zero, the crucial expression to determine the sign is $q-r_{A}$. With $\mathrm{q}>\mathrm{r}_{\mathrm{A}}$ there will be investment in the world fund. If $\mathrm{q}<\mathrm{r}_{\mathrm{A}}$ we will have a corner solution, where there is only investment in the individual portfolio. This is assuming short sales are prohibited. Plugging equation [2] in equation [1] results in the utility of the accepting investor

$\mathrm{U}_{\mathrm{c}}^{\mathrm{A}}=\frac{\left(\mathrm{q}-\mathrm{r}_{\mathrm{A}}\right)(\mathrm{J}-1)}{2 \gamma \sigma^{2}}+\mathrm{r}_{\mathrm{A}}$

The numerator shows the benefit of the revenue due to investment in the world portfolio while the denominator expresses individual risk weighting. Overall utility depends on the first term as well as on the rate of revenue after rescheduling $r_{A}$. If $q>r_{A}$ the first term has a positive sign. On the other hand, if $\mathrm{q}<\mathrm{r}_{\mathrm{A}}$ utility is negative, because the investor will holdout so we have to focus on the expected utility of the holdout investor. In this case, only the individual portfolio will receive investment, as the rate of return in the case of a rescheduling is always lager than world portfolios' rate of return. Utility is increasing in the amounts of assets and decreasing with risk aversion and risk level.

The investor who does not accept the restructuring offer considers the following expected utility function

$\mathrm{EU}_{\mathrm{c}}^{\mathrm{D}}=\propto^{\mathrm{D}} \mathrm{q}+\left(1-\propto^{\mathrm{D}}\right) \mathrm{r}-\frac{\gamma}{2}\left(\frac{\left(\alpha^{\mathrm{D} \sigma}\right)^{2}}{\mathrm{~J}-1}+\left(1-\propto^{\mathrm{D}}\right)^{2} \sigma^{2}\right)-\mathrm{K}$,

where index D represents the rejection of the restructuring offer. The refusing investor's expected utility depends on the return of the world fund and the return on the individual portfolio. This is similar to the investor who accepts. The variance depends on the investor's risk aversion and on the variance of the world fund. Furthermore, the expected utility is contingent on the individual variance of the private portfolio, because the holdout payout is risky. The costs $\mathrm{K}$ are consistent with the costs which arise during a holdout. There could be costs for legal proceedings (e.g. Argentina) or costs for collecting on outstanding bills (e.g. seizure of ships or planes). The approach is similar to that for the investor who accepts the restructuring. Therefore, the expected utility will be derived with respect to $\propto^{\mathrm{D}}$ and solved to

$\alpha^{\mathrm{D}}=\frac{\mathrm{J}-1}{\mathrm{~J}}\left[\frac{\mathrm{q}-\mathrm{r}}{\gamma \sigma^{2}}+1\right]$

The more assets are existent, the more worthwhile it is to invest in the world fund, because of the greater degree of diversification. This can be observed in the first term of equation [6]. The 
proportion of funds, which the holdout investor places into the world fund depends on the number of assets $\mathbf{J}$ and the terms in the bracket. If $\mathbf{J}$ increases, the bracket converges to one. However, the term before the bracket is $0,5 \leq \frac{\mathrm{J}-1}{\mathrm{~J}} \leq 1$. Given that $\mathrm{q}-\mathrm{r}<0$ and $\mathrm{r}-\mathrm{q}>\gamma \sigma^{2}$, equation [5] is negative and it results in a corner solution. This means that she will exclusively invest in the world fund. If $r-q<\gamma \sigma^{2}$, there will be an investment in both portfolios. The optimal portion which will be invested into the world fund is inserted into the expected utility function to

$\mathrm{EU}_{\mathrm{c}}^{\mathrm{D}}=\mathrm{r}-\frac{\gamma \sigma^{2}}{2 \mathrm{~J}}+\frac{(\mathrm{q}-\mathrm{r})(\mathrm{J}-1)}{\mathrm{J}}\left[1+\frac{\mathrm{q}-\mathrm{r}}{2 \gamma \sigma^{2}}\right]-\mathrm{K}$

The expected utility is positively correlated to the expected return of the individual portfolio. The second term shows the reduction of risk through diversification and is always negative. But the term decreases with the number of assets, so greater diversification reduces the risk and increases the expected utility. The third term is also negative, as $q-r<0$, which represents the revenue loss per asset of the world fund, if the holdout is successful. The higher $\mathbf{J}$ is, the faster the term converges to -1 . The value in the bracket can be larger or smaller than zero. The second term in the bracket indicates the individual risk-weighted revenue through the holdout. If the second term in the bracket is $r-q>2 \gamma \sigma^{2}$, the multiplication of the bracket and the term in front of it will be positive. The costs of the holdout are negative and will reduce the expected utility of the investor. If equation [6] is smaller than zero, the investor will not holdout. This depends on the expenses, which are independent of the return and expected revenue.

To answer the initial question whether a holdout is beneficial or not, the difference between the utility of an accepting and a refusing investor. The sign of this equation is crucial for the decision of the investor. For this reason, we form the difference between utility and expected utility

$\mathrm{S}_{\mathrm{c}}=\mathrm{U}_{\mathrm{c}}^{\mathrm{A}}-\mathrm{EU}_{\mathrm{c}}^{\mathrm{D}}$

If $\mathrm{S}_{\mathrm{c}}>0$, an agreement to the restructuring is favorable. Otherwise the investor should holdout and must bear costs of achieving the complete return on the asset. If the investor is indifferent between agree and holdout we assume that she will accept the debt restructuring offer. We now insert equation [3] and [6] into equation [7], so that we obtain 
$\mathrm{S}_{\mathrm{c}}=\frac{\left(\mathrm{q}-\mathrm{r}_{\mathrm{A}}\right)(\mathrm{J}-1)}{2 \gamma \sigma^{2}}+\mathrm{r}_{\mathrm{A}}-\left[\mathrm{r}-\frac{\gamma \sigma^{2}}{2 \mathrm{~J}}+\frac{(\mathrm{q}-\mathrm{r})(\mathrm{J}-1)}{2 \mathrm{~J}}\left[2+\frac{\mathrm{q}-\mathrm{r}}{\gamma \sigma^{2}}\right]-\mathrm{K}\right]$

Since $\gamma, \sigma^{2}>0, \mathrm{~J}>2$ and $\mathrm{r}_{\mathrm{A}}<\mathrm{q}<\mathrm{r},{ }^{5}$ it follows that

$\mathrm{S}_{\mathrm{c}}=\frac{\left(\mathrm{q}-\mathrm{r}_{\mathrm{A}}\right)(\mathrm{J}-1)}{2 \gamma \sigma^{2}}+\mathrm{r}_{\mathrm{A}}-\mathrm{r}+\frac{\gamma \sigma^{2}}{2 \mathrm{~J}}+\frac{(\mathrm{r}-\mathrm{q})(\mathrm{J}-1)}{\mathrm{J}}-\frac{(\mathrm{q}-\mathrm{r})^{2}(\mathrm{~J}-1)}{2 \mathrm{~J} \gamma \sigma^{2}}+\mathrm{K}$

It can be seen that the third and the sixth terms are negative and all other terms are positive. This suggests that an agreement is advantageous if

$\frac{\left(\mathrm{q}-\mathrm{r}_{\mathrm{A}}\right)}{2 \gamma \sigma^{2}}+\frac{\mathrm{r}_{\mathrm{A}}}{\mathrm{J}-1}+\frac{\gamma \sigma^{2}}{2 \mathrm{~J}(\mathrm{~J}-1)}+\frac{(\mathrm{r}-\mathrm{q})}{\mathrm{J}}+\frac{\mathrm{K}}{\mathrm{J}-1} \geq \frac{\mathrm{r}}{\mathrm{J}-1}+\frac{(\mathrm{q}-\mathrm{r})^{2}}{2 \mathrm{~J} \gamma \sigma^{2}}$

holds. In this case, an investor will agree to a debt restructuring. ${ }^{6}$

The higher $\mathrm{K}$ is, the less advantageous a holdout is from equation [9]. Thus, the likelihood of an agreement for debt restructuring increases with the costs that would be incurred. ${ }^{7}$

A holdout is at the inverse case

$\frac{\left(\mathrm{q}-\mathrm{r}_{\mathrm{A}}\right)}{2 \gamma \sigma^{2}}+\frac{\mathrm{r}_{\mathrm{A}}}{\mathrm{J}-1}+\frac{\gamma \sigma^{2}}{2 \mathrm{~J}(\mathrm{~J}-1)}+\frac{(\mathrm{r}-\mathrm{q})}{\mathrm{J}}+\frac{\mathrm{K}}{\mathrm{J}-1}<\frac{\mathrm{r}}{\mathrm{J}-1}+\frac{(\mathrm{q}-\mathrm{r})^{2}}{2 J \gamma \sigma^{2}}$

In this case, the expected profit of a holdout must be greater than its costs. Furthermore, it must compensate for the risks taken, which depends on the individual risk aversion and differs between investors c. If the holdout problem can be explained by free-rider behavior, equation [11] must be valid for all investors. Then, the reasonable strategy for each investor is to holdout and not to approve the debt restructuring. However, especially with smaller debt restructurings we observe that high approval rates are achieved. ${ }^{8}$ We explain those approval rates that these countries make up a small part of the investor's portfolio and thus the expected profits from a holdout exceed the costs. If this is true, the holdout problem cannot be explained by the free

\footnotetext{
${ }^{5}$ If $q \geq r$, the investor would invest in the world fund, since she would obtain an equal or greater return and she has a lower risk due to the diversification. Furthermore, it would be possible that $r_{A} \geq q$, as a restructuring is accompanied by a haircut, so that the yield is below that of the world portfolio.

${ }^{6} \mathrm{We}$ neglect the possibility that a national government exerts pressure on an investor and thus influences her decision. Sometimes this occurs such as when pressure was applied to major European investors during the Greece debt restructuring. However, this does not apply to all debt restructuring processes, as due to the common currency, Greece can been seen as an exception.

${ }^{7}$ This is consistent with Roubini (2002) who described that only a few investors would holdout due to the high costs.

${ }^{8}$ For example: Pakistan had an approval rate $99 \%$ with a Haircut of $31 \%$, Ukraine had an approval rate $97 \%$ with a Haircut of $28 \%$, Russia had an approval rate $99 \%$ with a Haircut of $67 \%$, Ecuador had an approval rate $98 \%$ with a Haircut of $27 \%$ and Iraq had an approval rate $96 \%$ with a Haircut of $98.9 \%$ (Sturzenegger and Zetelmeyer 2008).
} 
rider problem. Therefore, in the following we will analyze in more detail what drives the decision making of a risk adverse investor. In particular, an investor's decision making depends on the three returns, the costs and the number of invested assets. The exact role of these variables on the decision of an investor is explained below.

Expectations about governmental payment

The governmental payment to all investors is a function of $\mathrm{Z}$, which describes the highest possible amount a debtor could pay. Therefore, all $\mathrm{N}$ bonds could get the highest possible average rate of return $\mathrm{z}$, given that $\mathrm{Z}=\mathrm{Nz}$. According to Yeyati and Panizza (2011) the GDP during a haircut is at its bottom and increases afterwards. Should the creditors expect a rapid improvement of the conditions, they can speculate on a holdout. However, Tomz and Wright (2007) do not expect the GDP to be at its local low during the restructuring, but with deferral. Thus it is not beneficial to wait for an improvement in economic performance in order to generate a greater return on investment. This amount $\mathrm{Z}$ can be divided between all investors who accept and all holdout investors, so that

$\mathrm{Z}=\mathrm{N}\left(\beta \mathrm{r}_{\mathrm{A}}+(1-\beta) \mathrm{r}\right)$

where $\beta$ is the share of investors who accept and $(1-\beta)$ is the share of holdout investors. Equation [12] is solved for

$\mathrm{r}=\frac{\mathrm{z}-\beta \mathrm{r}_{\mathrm{A}}}{(1-\beta)}$

The unsecure rate of return depends on the share of investors who accepts and the deviation between the secure rate of return which the debtor offers and the possible average payment. The risky rate of return depends on investors expectations about the payment and the behavior of other investors. If equation [13] is plugged into the objective function the crucial investment decision is given by

$S_{C}=\frac{\left(q-r_{A}\right)(J-1)}{2 \gamma \sigma^{2}}+r_{A}-\frac{z-\beta r_{A}}{(1-\beta)}+\frac{\gamma \sigma^{2}}{2 J}+\frac{\left(\frac{z-\beta r_{A}}{(1-\beta)}-q\right)(J-1)}{J}-\frac{\left(q-\frac{z-\beta r_{A}}{(1-\beta)}\right)^{2}(J-1)}{2 J \gamma \sigma^{2}}+K$

If $\mathrm{z}$ is increasing the rate of return also increases and a holdout becomes more advantageous. Therefore, the investor's decision depends on the expected behavior of other investors and her 
expectation about the debtor's possible payment. The derivation of S with respect to $\mathrm{z}$, expected possible payment

$\frac{\partial S_{c}}{\partial z}=-\frac{\left(-\frac{\mathrm{q}}{1-\beta}+\frac{\mathrm{z}-\beta \mathrm{r}_{\mathrm{A}}}{(1-\beta)^{2}}\right)(\mathrm{J}-1)}{\mathrm{J} \gamma \sigma^{2}}-\frac{1}{(1-\beta) \mathrm{J}}<0$

applies, so that the derivation of $\mathrm{S}_{\mathrm{c}}$ with respect to $\mathrm{z}$ is smaller than zero. This means that it is advantageous to holdout, if the expected possible payment increases in non-agreement. The higher the profit expectations of a holdout, the more likely the investor will holdout. This applies to the case that $\frac{\mathrm{z}-\beta \mathrm{r}_{\mathrm{A}}}{(1-\beta)}>\mathrm{q}$. This assumption reflects that the investor would not invest in the individual asset, if the world portfolio promised the same or a greater rate of return. The first term expresses the risk weighted profit during a holdout. It increases with an increase in the difference between the holdout return and the yield of the world fund. For this reason, the derivative is negative, so that an increase of holdout return makes a holdout more advantageous. However, holdout willingness decreases with an increase of $\mathbf{J}$ and a large variance. This means that a holdout on a small number of assets and a low variance is particularly advantageous.

\section{Proposition 1}

Increasing diversification result in higher approval rates.

To proof we assume that $\mathrm{J} \rightarrow \infty$,

$\lim _{J \rightarrow \infty} \frac{\left(q-r_{A}\right)}{2 \gamma \sigma^{2}}+\frac{r_{A}}{J-1}+\frac{\gamma \sigma^{2}}{2 J(J-1)}+\frac{\left(\frac{z-\beta r_{A}}{(1-\beta)}-q\right)}{J}+\frac{K}{J-1}-\frac{\frac{z-\beta r_{A}}{(1-\beta)}}{J-1}-\frac{\left(q-\frac{z-\beta r_{A}}{(1-\beta)}\right)^{2}}{2 J \gamma \sigma^{2}} \rightarrow \frac{\left(q-r_{A}\right)}{2 \gamma \sigma^{2}}$

An increase of $\mathrm{J}$ results in a positive value of equation [16], so that for a variety of investment opportunities an agreement is beneficial. This is true for the assumption that $q>r_{A}$. Sturzenegger and Zetelmeyer (2008) as well as Cruces and Trebesch (2013) analyze investor losses in restructurings with bondholders and foreign banks. One half of the haircuts are above $53 \%$ so that the assumption holds. Furthermore, the largest restructurings implied haircuts of more than $50 \%$. The only sovereign restructuring where the assumption does not hold is the Dominican Republic 2004 with a haircut of 4.7 \% (Cruces and Trebesch 2013).

For many investment opportunities, the advantage of an agreement comes from the risk weighted return of the yield different on an investment in the world fund and the agreed return. 
This is the utility advantage, which an investor who approves a restructuring would achieve, compared to an investor holding out, if $\mathrm{J}$ increases. If $\mathrm{J}$ is small, and by assumption $\mathrm{J}$ should be $2<\mathrm{J}<\infty$, the decision depends on the constellation of the single variables. For this reason, equation [14] can be positive or negative. This can be justified if the level of diversification in the world portfolio is low due to a small number of assets. As a consequence, this will increase the proportion of funds that is invested in the individual portfolio. Therefore, a holdout could become more beneficial for the investor due to higher risk of the world fund. It depends on the single returns, the costs and the variance. This is the reason why a situation exists in which some investors agree and others holdout. It also explains the different levels of agreement during a debt restructuring and why different investors make different decisions.

\section{Proposition 2}

An increase in the returns of the world fund reduces the incentive to holdout. An increase of the debt restructuring offer takes effect in both directions.

To show this the objective function of the investor [14] is maximized according to the considered variables. The value of the function depends on single returns of the investor. However, the returns of the two portfolios and the return of the investor who agrees as well as that of the holdout investor act in different directions. To find out how the objective function acts under a change of the yield, we derive equation [14] according to the returns $q$ und $r_{A}$.

The yield of the world fund q acts in another direction. The higher the return on the world fund, the more likely the investor agrees to a restructuring. To determine the influence of $q$ on the investor's decision, we will derive $S_{c}$ with respect to q. Given by

$\frac{\partial \mathrm{S}_{\mathrm{c}}}{\partial \mathrm{q}}=\frac{\mathrm{J}-1}{2 \gamma \sigma^{2}}+\frac{\left(\frac{\mathrm{z}-\beta \mathrm{r}_{\mathrm{A}}}{(1-\beta)}-\mathrm{q}\right)(\mathrm{J}-1)}{\mathrm{J} \gamma \sigma^{2}}-\frac{\mathrm{J}-1}{\mathrm{~J}}=\frac{\mathrm{J}-1}{2 \gamma \sigma^{2}}+(\mathrm{J}-1) \frac{\frac{\mathrm{z}-\beta \mathrm{r}_{\mathrm{A}}}{(1-\beta)}-\mathrm{q}-\gamma \sigma^{2}}{\mathrm{~J} \gamma \sigma^{2}}$.

Given that $\frac{z-\beta r_{A}}{(1-\beta)}>q+\gamma \sigma^{2}$ applies, the second term of equation [14] is positive, which expresses the revenue loss per asset, as soon as the investor invests in the world fund and does not holdout. The first term shows the reduction of risk due to a better diversification and depends only on positive variables, so that it is always positive. The third term is negative. If $\mathbf{J}$ is large, the approval rate rises. Given that $J=2$ and $\frac{z-\beta r_{A}}{(1-\beta)}<q+\frac{\gamma \sigma^{2}}{2}$ a holdout would be 
beneficial, if the return of the world fund increases. For this to occur, a sufficiently large variance is necessary.

The influence of $r_{A}$ on the investor's decision is ambiguous. The derivative of $S_{c}$ with respect to $r_{\mathrm{A}}$

$\frac{\partial \mathrm{S}_{\mathrm{c}}}{\partial \mathrm{r}_{\mathrm{A}}}=1-\frac{\mathrm{J}-1}{2 \gamma \sigma^{2}}+\frac{\beta}{\mathrm{J}(1-\beta)}+\frac{\left(-\frac{\mathrm{q}}{1-\beta}+\frac{\mathrm{z}-\beta \mathrm{r}_{\mathrm{A}}}{(1-\beta)^{2}}\right)(\mathrm{J}-1)}{\mathrm{J} \gamma \sigma^{2}} \lesseqgtr 0$

shows that no explicit statement is possible. The first term is always positive and the second term of equation [18] is always negative, because the variance and the risk aversion parameter are positive and $\mathrm{J}$ is larger than 2 . If the number of assets increases the numerator also increases. Thus, the derivative of $\mathrm{S}$ with respect to $\mathrm{r}_{\mathrm{A}}$ decreases and a holdout becomes more advantageous.

\section{Proposition 3}

An increase of $q$ and $r_{A}$ leads to an increase in the acceptance rate of investors during a sovereign debt restructuring.

To determine the change in the difference between $q$ and $r_{A}$, we form the total differential of equation [14] and obtain the following equation

$\mathrm{dS}_{\mathrm{c}}=\left[\frac{\mathrm{J}-1}{2 \gamma \sigma^{2}}+(\mathrm{J}-1) \frac{\frac{\mathrm{z}-\beta \mathrm{r}_{\mathrm{A}}}{(1-\beta)}-\mathrm{q}-\gamma \sigma^{2}}{\mathrm{~J} \gamma \sigma^{2}}\right] \mathrm{dq}+\left[1-\frac{\mathrm{J}-1}{2 \gamma \sigma^{2}}+\frac{\beta}{\mathrm{J}(1-\beta)}+\frac{\left(-\frac{\mathrm{q}}{1-\beta}+\frac{\mathrm{z}-\beta \mathrm{r}_{\mathrm{A}}}{(1-\beta)^{2}}\right)(\mathrm{J}-1)}{\mathrm{J} \gamma \sigma^{2}}\right] \mathrm{dr}_{\mathrm{A}}>0$

Equation [19] is positive since $\frac{z-\beta r_{A}}{(1-\beta)}>q$. The total differential shows that a simultaneous, infinitesimal change of the two variables increases the function $S_{c}$. This means that a change of $\mathrm{q}$ and $\mathrm{r}_{\mathrm{A}}$ implies a rise of the agreement by the investor. The increase of $\mathrm{q}$ is decisive since a gain in the return of the world portfolio makes an investment in the individual portfolio unattractive. Therefore, the rise of $\mathrm{q}$ leads to an increase of the agreement rate. 


\section{Proposition 4}

Correlation between returns does not affect the results and the direction in which the individual variables act. A larger $J$ is more advantageous for the acceptance of the offer. The cost $K$ also increases the likelihood of agreement to the restructuring. The return of the world portfolio and the individual portfolio pulls in different directions.

If we allow correlation $\theta \neq 0$, the utility function of the accepting investor does not change. She has no risk since she takes the safe payment and therefore there cannot be any correlation with the returns. The utility function of the investor who does not agree will change to

$E U_{c}^{D}=\propto^{D} q+\left(1-\propto^{D}\right) \frac{z-\beta r_{A}}{(1-\beta)}-\frac{\gamma \sigma^{2}}{2}\left(\frac{\left(\alpha^{D}\right)^{2}}{J-1}+\left(1-\propto^{D}\right)^{2}+2 \theta \alpha\left(1-\propto^{D}\right)\right)-K$

The procedure is equivalent to the no-correlation case, so we derive with respect to $\propto^{\mathrm{D}}$

$\frac{\partial \mathrm{EU}_{\mathrm{c}}^{\mathrm{D}}}{\partial \propto^{\mathrm{D}}}=\mathrm{q}-\frac{\mathrm{z}-\beta \mathrm{r}_{\mathrm{A}}}{(1-\beta)}-\frac{\gamma \sigma^{2}}{2}\left[\frac{2 \alpha^{\mathrm{D}}}{\mathrm{J}-1}+2 \propto^{\mathrm{D}}-2+2 \theta-4 \theta \propto^{\mathrm{D}}\right]$

We solve for the share $\alpha^{\mathrm{D}}$, which is invested in the world portfolio and obtain

$\propto^{\mathrm{D}}=\frac{\mathrm{J}-1}{\mathrm{~J}-2 \mathrm{~J} \theta+2 \theta}\left[1+\frac{\mathrm{q}-\frac{\mathrm{z}-\beta \mathrm{r}_{\mathrm{A}}}{(1-\beta)}}{\gamma \sigma^{2}}-\theta\right]$.

We than substitute equation [23] into equation [21] and receive the expected utility function for non-approval investors

$\mathrm{EU}_{\mathrm{c}}^{\mathrm{D}}=\frac{\mathrm{z}-\beta \mathrm{r}_{\mathrm{A}}}{(1-\beta)}-\frac{\gamma \sigma^{2}}{2}+\frac{\mathrm{J}-1}{\mathrm{~J}-2 \theta(\mathrm{J}-1)}\left[\left(\mathrm{q}-\frac{\mathrm{z}-\beta \mathrm{r}_{\mathrm{A}}}{(1-\beta)}\right)+(1-\theta) \gamma \sigma^{2}\right]^{2} \frac{1}{2 \gamma \sigma^{2}}-\mathrm{K}$.

The expected utility function is positively related to the expected return of the assets and negatively related to the variance and the level of risk aversion. The third term depends on the correlation between the assets, so the factor prior to the bracket is negative, if $\theta>\frac{\mathrm{J}}{2(\mathrm{~J}-1)}$.

The crucial factor is whether the expected utility of non-approval is larger or smaller than the utility of approving restructuring. For this reason, we take the difference of the two functions to obtain

$S_{c}=\frac{\left(q-r_{A}\right)(J-1)}{2 \gamma \sigma^{2}}+r_{A}-\frac{z-\beta r_{A}}{(1-\beta)}+K+\frac{\gamma \sigma^{2}}{2 J}-\frac{J-1}{J-2 \theta(J-1)}\left[\left(q-\frac{z-\beta r_{A}}{(1-\beta)}\right)+(1-\theta) \gamma \sigma^{2}\right]^{2} \frac{1}{2 \gamma \sigma^{2}}$. 
The first four terms are also included in equation [14], while the last term is different. If we set $\theta=0$ in equation [25] we generate the original equation without correlation. As in the case without correlation, it is crucial to find what influences the decision of approving a restructuring. The investor will always agree to a debt restructuring, if the expression in the bracket is zero and $r_{A}+K>\frac{z-\beta r_{A}}{(1-\beta)}$. If this case does not apply, the number of invested assets, the yield spreads on the assets and the correlation between returns are relevant for the investors' decision. The larger $\mathrm{K}$ is, the more advantageous it is to approve the restructuring. This is equivalent to the case with no correlation. In the following section we analyze which variable is decisive for the investor's decision and how this decision alters with correlation.

The more assets the investor holds, the more rational it is to agree to a debt restructuring. The first and last term depend on $\mathrm{J}$. If $\mathrm{J}$ is a large number the first term will dominate and the investor will agree to the restructuring. If $\mathrm{J}$ takes a small value that is greater than 2 , the decision will depend on correlation and the other variables. This finding is similar to the case with no correlation. If the correlation is sufficiently large, the last term will be positive and the investor will approve to the debt restructuring. If the correlation is small, the decision on the restructuring will depend on the other variables.

How does $S_{c}$ vary by a change of $r_{A}$ und $q$ ? To answer this question, we need to derive equation [25] with respect to the decision variables $r_{A}$ und $q$. The derivative with respect to the return of the world portfolio q does not change from the case with no-correlation. We obtain

$\frac{\partial \mathrm{S}_{\mathrm{c}}}{\partial \mathrm{q}}=\frac{\mathrm{J}-1}{2 \gamma \sigma^{2}}+\frac{\mathrm{J}-1}{\mathrm{~J}-2 \theta(\mathrm{J}-1)}\left(\frac{\mathrm{q}-\frac{\mathrm{z}-\beta \mathrm{r}_{\mathrm{A}}}{(1-\beta)}}{\gamma \sigma^{2}}+\frac{1-\theta}{2}\right)$.

It is not clear if the derivative is positive. In a case of a large yield difference between the individual portfolio during a holdout and the world portfolio, in combination with a correlation bigger than $\theta \geq \frac{\mathrm{J}}{2(\mathrm{~J}-1)}$, the derivative can become negative. Once the return on the world portfolio rises, the investor will agree to a debt restructuring. This is due to the fact that the difference in the yield between her individual and the world portfolio becomes smaller. An exception occurs if there is a sufficiently large correlation between returns and returns are strongly interrelated. Therefore an investment in the individual's portfolio is advantageous. This can result in a holdout by the investor.

The same applies to the derivative with respect to the accepted return. The derivative will not differ from the case without correlation, since the acceptance of the offer will not change the 
yield. Therefore there is no correlation between the accepted return and the return of the world portfolio. Equation [18] does not change if correlation is present.

$\frac{\partial \mathrm{S}_{\mathrm{c}}}{\partial \mathrm{r}_{\mathrm{A}}}=1-\frac{\mathrm{J}-1}{2 \gamma \sigma^{2}}+\frac{\beta}{1-\beta}-\frac{\mathrm{J}-1}{[\mathrm{~J}-2 \theta(\mathrm{J}-1)] \gamma \sigma^{2}}\left[\left(\mathrm{q}-\frac{\mathrm{z}-\beta \mathrm{r}_{\mathrm{A}}}{(1-\beta)}\right)+(1-\theta) \gamma \sigma^{2}\right] \frac{\beta}{1-\beta}$

We form the total differential for equation [26] in with respect to $q$ and $r_{A}$. We do this in order to see what the deviation is for the return if the restructuring is accepted and the return of the world portfolio in the correlation case. Additionally, we want to see if the result changes by allowing correlation. In this case, all other variables are assumed to be constant. So that we receive the following equation

$\mathrm{dS}_{\mathrm{c}}=\left[\frac{\partial \mathrm{S}}{\partial \mathrm{q}}=\frac{\mathrm{J}-1}{2 \gamma \sigma^{2}}+\frac{\mathrm{J}-1}{\mathrm{~J}-2 \theta(\mathrm{J}-1)}\left(\frac{\mathrm{q}-\frac{\mathrm{z}-\beta \mathrm{r}_{\mathrm{A}}}{(1-\beta)}}{\gamma \sigma^{2}}+\frac{1-\theta}{2}\right)\right] \mathrm{dq}+\left[1-\frac{\mathrm{J}-1}{2 \gamma \sigma^{2}}+\frac{\beta}{1-\beta}-\frac{\mathrm{J}-1}{[\mathrm{~J}-2 \theta(\mathrm{J}-1)] \gamma \sigma^{2}}[(\mathrm{q}-\right.$

$\left.\left.\left.\frac{\mathrm{z}-\beta \mathrm{r}_{\mathrm{A}}}{(1-\beta)}\right)+(1-\theta) \gamma \sigma^{2}\right] \frac{\beta}{1-\beta}\right] \mathrm{dr}_{\mathrm{A}}$.

Equation [29] shows that the result does not change by the inclusion of correlation. A simultaneous, infinitesimal change of $\mathrm{q}$ and $\mathrm{r}_{\mathrm{A}}$ leads to an increase in the function, therefore the investor will more likely agree to a restructuring.

In summary, one can conclude that the decision of the investor is independent of the correlation between the assets. The key variables are the number of invested assets and the difference in returns between the individual and world portfolios. ${ }^{9}$

\section{Debt restructuring in Argentina and Greece}

In the following section, the model will be applied to the debt restructuring in Greece and Argentina. ${ }^{10}$ Sturzenegger and Zettelmeyer (2008) analysed the haircuts during the restructuring in 1998 and 2005. Investors' losses were defined as

$\mathrm{H}=1-\frac{\text { Market value new bond }}{\text { Cash value old bond }}$.

Argentina, however, experienced the restructuring with the highest loss at a haircut of $73 \%$. The distribution of creditors' waivers resulted in clumps, so creditors either waived about $20 \%$

\footnotetext{
${ }^{9}$ One quite interesting feature is how the decision of the investor is changed by the assumption that the payout for holdout is dependent on the decisions of other investors.

${ }^{10}$ Uruguay carried out the lowest haircut at $13 \%$, because the restructuring took place in terms of a fair and friendly environment.
} 
or approximately $60 \%$. Due to the two authors' analysis, we assume $r_{A}=0.27$ for Argentina (Sturzenegger and Zettelmeyer 2008). Creditors who did not consent have not received any money to this day. However, there are lawsuits pending before a US court, in which holdout investors are taking legal action against the full repayment stipulated in the bond contracts. The nominal loss during the Greek debt restructuring was $53.5 \%$ of the par value. However, interest payments are much lower in the newly restructured bonds, so creditors' losses are estimated to be about $70 \%$. In this case, we assume a $r_{A}=0.3$.

Lewis (1996) analysed the premium of shares by means of investors' risk aversion. The risk aversion for equities is higher than for bonds. Wachter (2001) argues that risk-averse individuals prefer a secure payment and should therefore buy long-term bonds. The asset with the least risk for is a bond with the investor's time horizon. Hansen and Singleton (1983) estimated the risk aversion coefficient to be between zero and two. Calvo and Mendoza (2000) found in an estimate based on numerous investors' portfolios that $\gamma$ must be between 0 and 0.5 . Therefore, they used the mean value of 0.25 in their analyses which we will follow in this paper. Of course risk aversion could be different between investors. The higher the risk aversion, the more likely the investor will agree.

In the case of Argentina $76 \%$ of investors agree. Therefore, we assume that merit for $\beta$. Greece had an acceptance rate of $86.8 \%$. Furthermore, the expected possible payment of a debtor is crucial for the investors' behavior. The higher the expected possible payment, the more likely the investor will holdout. In Figure 3 we use a value of 2.5 for $z .{ }^{11}$ If that value increases the holdout interval increases. Therefore, the expectation about the possibility of the payment is crucial for a holdout decision.

For the yields, 10-year government bonds from the respective countries have been used. In the case of Greece, the time period from August 2011 to March 2012 was assessed. Greece announced its national bankruptcy in August 2011 after it had been receiving financial aid since May 2010. The restructuring offer followed on 22 February 2012 and creditors were able to make a decision up to 8 March 2012, 9 pm CET. For this reason, the time from 22 February to 12 March 2012 is particularly interesting for our analysis.

\footnotetext{
${ }^{11}$ We use that value to plot figure 3-1 and 3-2.
} 
Figure $1 \quad$ Yield and volatility during the Greek debt restructuring

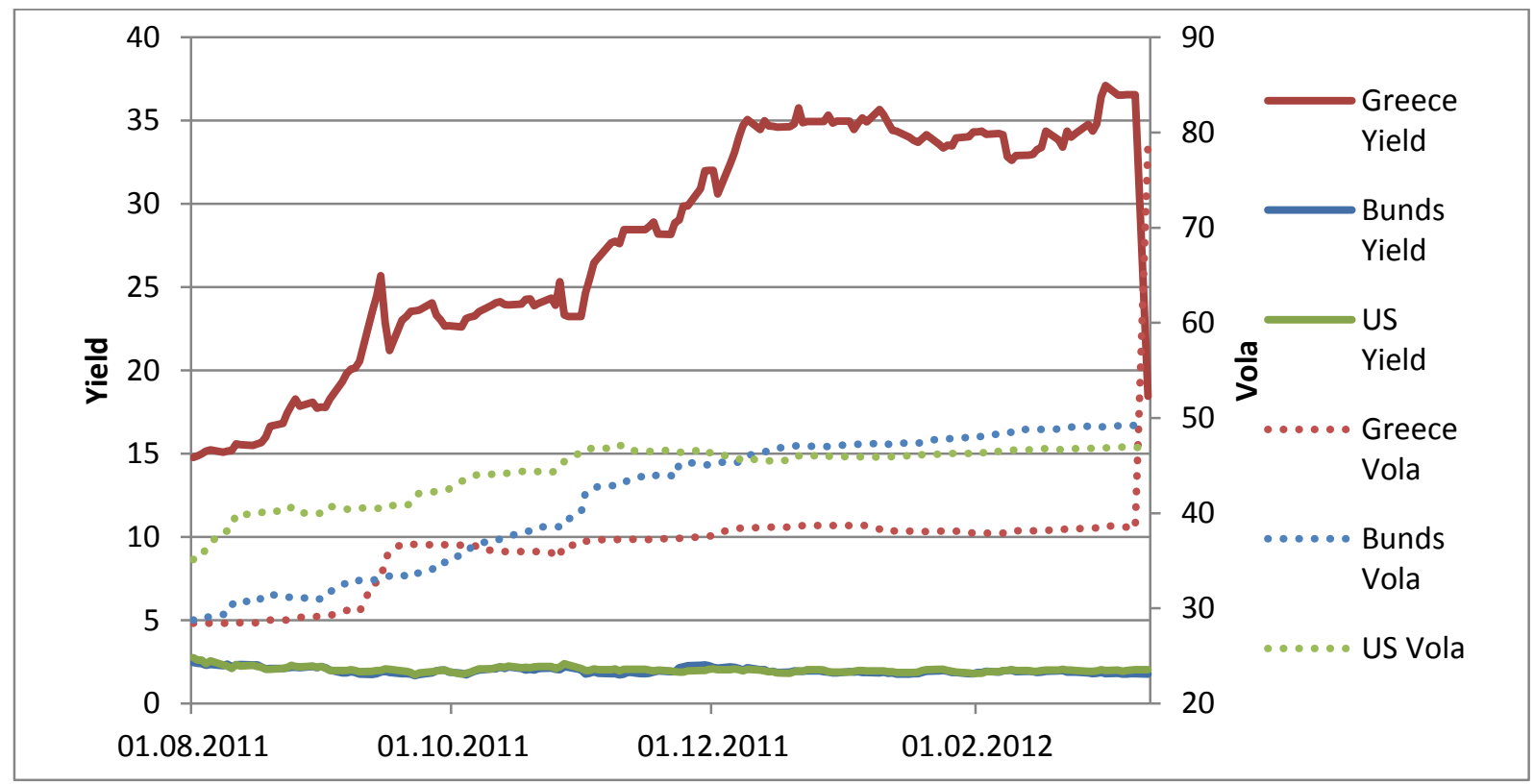

Source Bloomberg

It is interesting to take a look at the volatility of the traded bonds in the same time period. Yields for Greek, US and German bonds are shown on the left axis and characterised by the continuous line. It can be seen that yields in the USA and Germany are on a similar level below $2 \%$, while Greek bonds promised yields of $15 \%$ in August 2011. The yields increased in the course of time, which is why they reached their maximum of $37.101 \%$ during the restructuring process on 2 March 2012. German and US bonds were traded at $1.8 \%$ and $1.9739 \%$ at the same day. Volatility can be seen on the right axis and is characterised by a dotted line. It is noticeable that the volatility of Greek bonds is lower than for German or US bonds. After the restructuring process was completed, volatility increased due to the higher decline in yields and reached higher values than volatility in the two developed countries.

In the case of Argentina, President Saa (at that time, he had been President for 5 days) announced national bankruptcy on 23 December 2001. President Kirchner made the restructuring offer to creditors on 12 January 2005, which was announced to be completed on 25 February 2005. Therefore, the time period from 12 January to 28 February 2005 is particular of interest. In this case, we have compared yields and volatility in Argentina with the USA and Germany, which can be seen in Figure 2. 
Figure 2 Yield and volatility during the Argentine debt restructuring

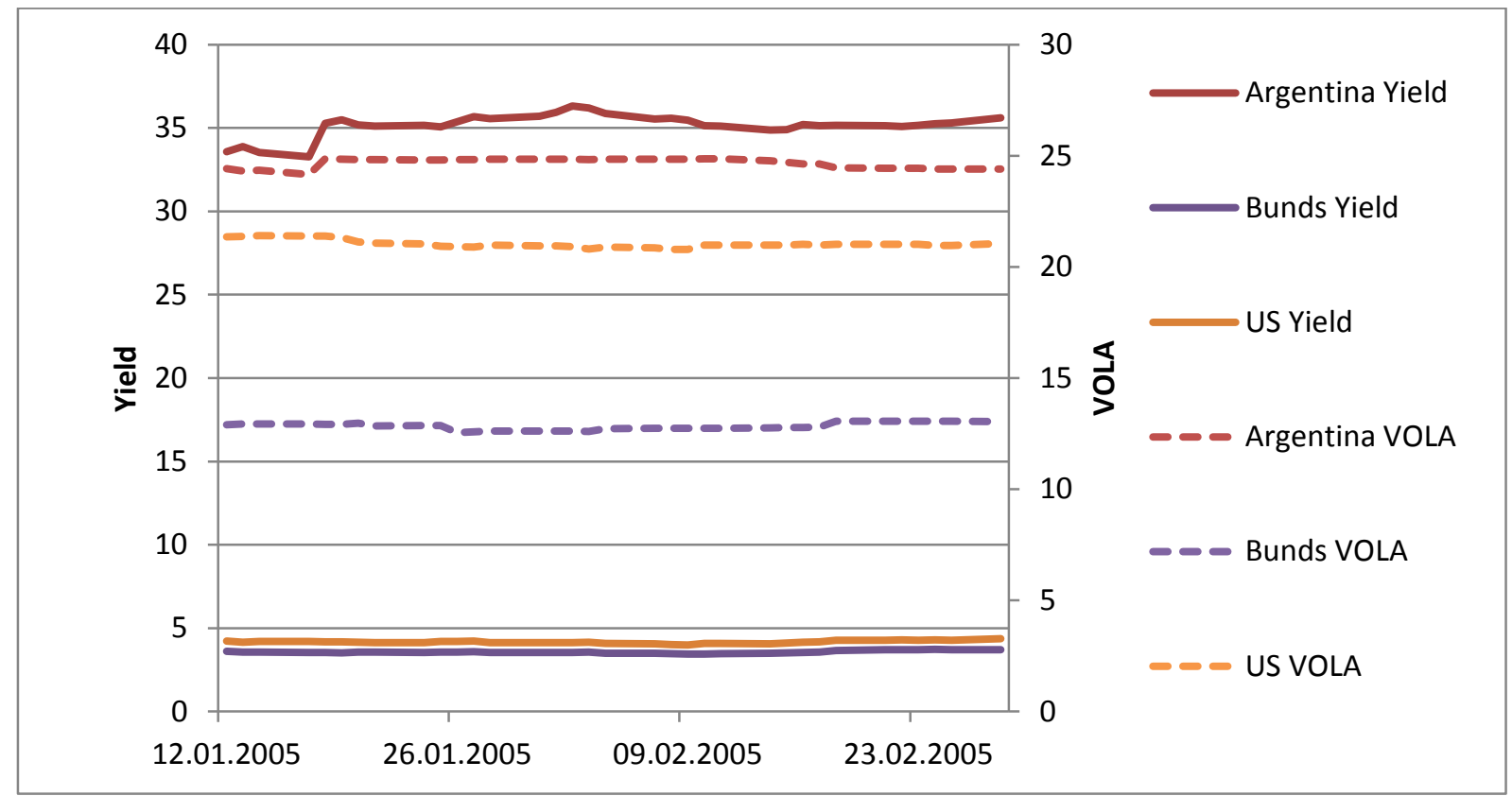

Source Bloomberg

Yields for German and US bonds of $3.445 \%$ and $4.0888 \%$ were much lower than for Argentine bonds of $35.131 \%$ on 10 February 2005. Contrary to Greece in 2012, volatility of Argentine bonds is higher than for the other two countries. Volatility and yields were constant over the period of time, which is different to Greece. In our model, we assumed uniform variances for all bonds. This is because volatility of bonds to be restructured is not always higher than volatility in the developed countries.

In the following graphs, we have illustrated an investor's decision-making criterion for the restructuring of Argentina and Greece. The left graph refers to the Argentine and the right to the Greek debt restructuring. The comparison was made between Argentine/Greek volatility (blue), US volatility (green) and German (orange). As the dates of decision, we set 10 February 2005 and 2 March 2012, because this is when yields reached their peak. Volatility in Argentina was 24.86, in the US 20.97 and in Germany 12.735 at the 10 February 2005. In the case of Greece (Figure 3-1), Greek volatility was 38.684, US 46.8745 and German 49.146 at the 2 March 2012. The vertical axis shows the decision-making criterion's benefit difference. The graph shows that a holdout is beneficial in negative terrain and consent is beneficial in positive terrain. The decision depends on the variance. In the case of Argentina (Figure 3-2), a holdout is more advantageous for less diversified investors with the German variance. If the variance is 
bigger, such as in the case of Greece, a holdout is more advantageous for more diversified investors. This is reflected by the German variance in figure 3-1 and 3-2.

Figure 3-1 Investors' considerations in the Greek case

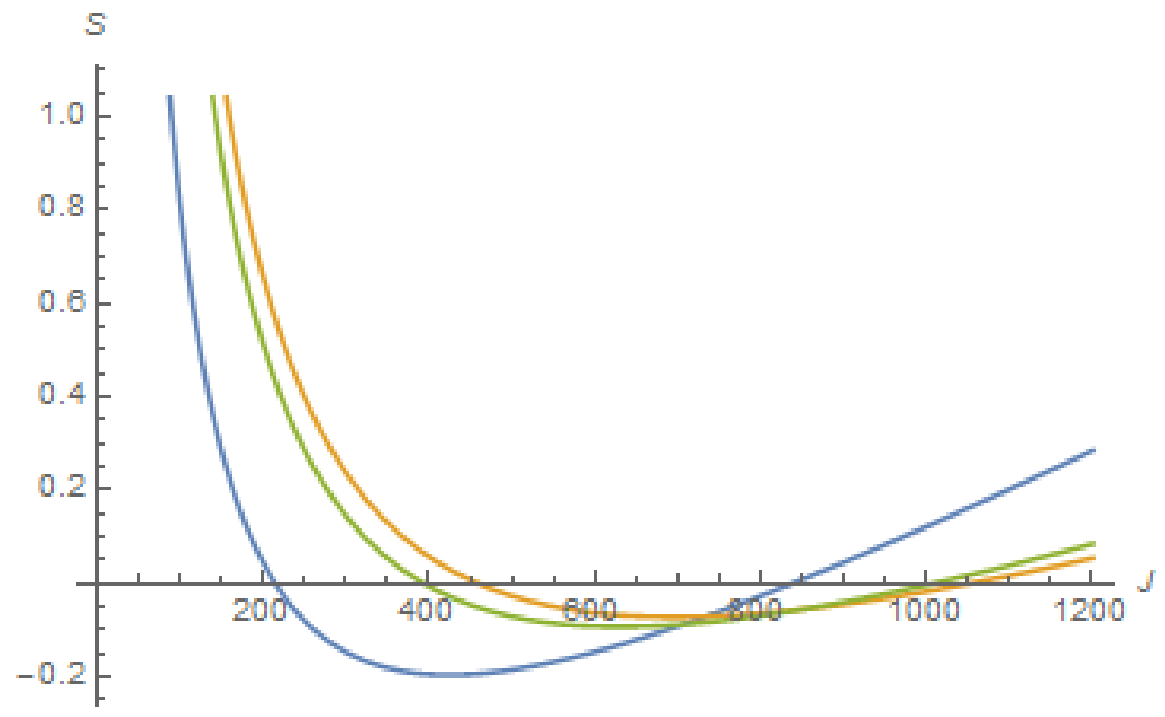

— Greek Volatility

- German Volatility

— US-Volatility

Figure 3-2 Investors' considerations in the Argentinian case

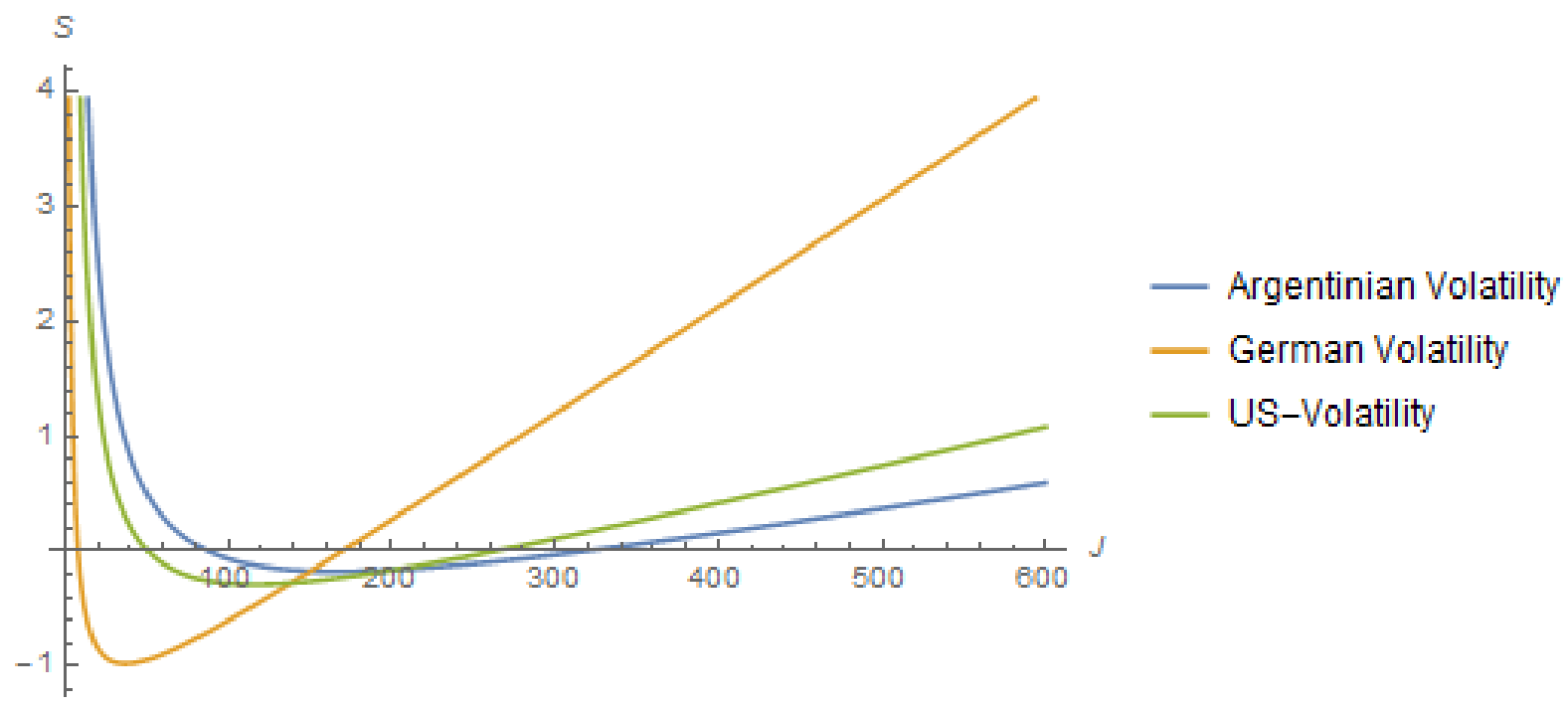


Figure 3-1 and 3-2 shows that increasing the variance results in the holdout area shifting to the right. This is because the gradient of the function reduces if the variance increases. The costs of a holdout, which are not considered in the graph, result in an upward shift of the function. The course of the curves shows that each restructuring includes an interval in which a holdout is more beneficial than consent. Therefore, this interval can be used as a reason why investors make a rational decision against restructuring without taking strategic aspects into account.

\section{Effects of the Collective Action Clause}

A CAC is a clause in bond contracts, according to which an amendment of the contract is possible if the majority of creditors consent. This amendment is binding for all creditors. As from June 2013, an identical CAC compatible with UK and US law has to be included in all EU government bond contracts. ${ }^{12}$ The aim is to facilitate sovereign debt restructuring, because there are numerous creditors that make negotiations between creditors and debtors difficult. Without CAC a minority of creditors do not consent to the negotiated result and attempt to push through full compliance with the contract, negotiations would fail. According to Weinschelbaum and Wynne (2005) the CAC can solve such a problem. If a CAC is introduced, this means that the incentive for a holdout reduces because there must be a sufficient number of investors to disagree with the restructuring. In most cases, this would be more than $25 \%$ of investors. However, a large number of investors disagreeing would lead to the fact that the likelihood of a full repayment reduces which is shown in equation [14]. According to the model from Engelen and Lambsdorff (2009), the yield does not decrease for a number of holdout investors. Investors will join forces and negotiate together for a higher holdout yield or for a full repayment, sharing costs at the same time. However, our model assumes numerous investors, who cannot join forces in the event of a restructuring. This leads to a coordination problem between creditors, which is why debtors are taken action against individually. Holdout investors cannot share costs in this case.

Furthermore, an information problem between debtors and creditors arises, so it is difficult for creditors to assess during the negotiations to what extent a haircut would be necessary in order to secure solvency of a sovereign state. Another information problem for creditors is that there

\footnotetext{
${ }^{12}$ http://www.bmwi.de/BMWi/Redaktion/PDF/Publikationen/Studien/gutachttext-ueberschuldungstaatsinsolvenz-in-der-eu-wissenschaftlicher-beirat, property=pdf, bereich=bmwi,sprache=de, rwb=true.pdf p. 21 Obtained on 29 Oct. 2013.
} 
is no definition as to when a sovereign state is insolvent and when it is not. Typically, the solvency of a sovereign state cannot be determined by economic figures ultimately. Yeyati and Panizza (2011) described that it is rational for a debtor to make a default as soon as market participants assume that the debtor has made a default. In an empirical study, the two authors determined that GDP is at a low at the time of the default and already increases again after the default (Yeyati and Panizza 2011). According to Haldane et al (2005), there may be inefficiencies during the negotiations between creditors. In this case information asymmetries are responsible for the coordination problem.

Investors have different expectations concerning the necessity of the haircut and the debtor's financial situation in the future. Therefore, the coordination problem can hardly be solved and investors will individually take legal action in order to push through the servicing of the debt. The $\mathrm{CAC}$ reduces the incentive for a holdout. If the CAC applies, the investor receives the secure yield $r_{A}$, although she does not consent to the restructuring. There are rational reasons for an investor not to consent to restructuring. This is what we described in sections 2 to 4 of the paper. This investor is invested in the asset to be restructured to a large extent and is therefore willing to make more effort to receive a higher yield than other investors who are sufficiently diversified. The CAC suppresses other investors' investment decisions. Shleifer (2003) described that the government bond market is characterised by hardly existent creditor protection. However, markets work in the most efficient way if there is sufficient creditor protection. It is therefore surprising that this market works. The CAC deprives non-diversified investors of more rights of debt collection. This makes the government bond market be even further away from creditor protection.

In the event the CAC does not apply, the investors can hold out. If the percentage of creditors who do not consent to a restructuring is high, the yield will decrease due to the large number of participants holding out. This is what the investor will include in her decision-making process. Therefore, the incentive for the investor to hold out decreases due to the implementation of a CAC.

\section{Conclusion}

The model presented illustrates that a holdout is by no means destructive investor behaviour but a rational investment decision. This decision depends on investor's portfolio structure and on the expected yields for the individual assets as well as the individual risk aversion. 
Depending on the portfolio structure, the investors will consent to the restructuring. This explains why the lowest consent rates could be seen during the biggest restructuring processes in terms of restructuring volume.

We assumed atomised investors in our model. This is the point in which our model is different to the model by Engelen and Lambsdorff (2009). However, a CAC leads to a reduction in this willingness to hold out. More detailed analyses are required to show what effect the CAC has on a holdout. Nevertheless, a CAC is an infringement of creditor protection, so a creditor may be forced to act against her will based on a majority decision. Furthermore, it could be analysed what effect an improved organisation of creditors, such as in the London Club or the former Corporation of Foreign Bondholders, has on the participants' decision. In such a case, strategic behaviour is possible and this kind of organisation would contribute to creditor protection. Moreover, such an organisation could distribute cost incurred during a holdout between all members and thus put more pressure on the debtor.

\section{References}

Bolton, P., \& Jeanne, O. (2009). Structuring and Restructuring Sovereign Debt: The Role of Seniority. Review of Economic Studies, pp. 879-902.

Calvo, G. A., \& Mendoza, E. G. (2000). Rational contagion and the globalization of securities markets. Journal of International Economics, pp. 79-113.

Chatterjee, K., \& Samuelson, W. (1983). Bargaining under Incomplete Information. Operation Research, pp. 835-851.

Coffee, J. C., \& Klein, W. A. (1991). The Problem of Constrained Choice in Debt Tender Offers and Recapitalization. The University of Chicago Law Review, pp. 1207-1273.

Daniels, K., \& Ramirez, G. G. (2007). Debt restructuring, holdouts and exit consents. Journal of Financial Stability, pp. 1-17.

Eichengreen, B. (2003). Restructuring Sovereign Debt. The Journal of Economic Perspectives, pp. 7598.

Eichengreen, B., \& Mody, A. (2004). Do collective action clauses raise borrowing costs? The Economic Journal, pp. 247-264.

Eichengreen, B., \& Portes, R. (1995). Crises? What crisis. In B. Eichengreen, L. Felli, J. R. Franks, C. Greenwood, H. Mercer, R. Porter, \& G. Vitale, Orderly Workouts for Sovereign Debtors. London: Centre for Economic Policy Research.

Engelen, C., \& Lambsdorff, J. G. (2009). Hares and stags in Argentinean restructuring. Journal of International Economics, pp. 141-148. 
Haldane, A. G., Penalver, A., Saporta, V., \& Shin, H. S. (2005). Analytics of sovereign debt restructuring. Journal of International Economics, pp. 315-333.

Helleiner, E. (2008). The mystery of the missing sovereign debt restructuring mechanism. Contributions to Political Economy, pp. 91-113.

Lewis, K. K. (1996). Consumption, Stock Returns, and the gain from International Risk-Sharing. Working paper No. 96-6.

Miller, M., \& Thomas, D. (2007). Sovereign debt restructuring: the judge, the vultures and the future of creditor rights. The World Economy, pp. 1491-1509.

Pitchford, R., \& Wright, M. L. (2011). Holdouts in Sovereign Debt Restructuring: A theory of negotiation in a weak contractual evironment. Review of Economic Studies, pp. 812-837.

Rogoff, K., \& Zettelmeyer, J. (2002). Bankruptcy Procedures for Sovereigns: A History of Ideas, 1976-2001. International Monetary Fund Staff Paper, pp. 470-507.

Roubini, N. (2002). Do we need a new bankruptcy regime. Brookings Papers on Economic Activity, pp. 321-333.

Shleifer, A. (2003). Debt, equity, and financial openness - Will the Sovereign Debt Market Survive. The American Economic Review, pp. 85-90.

Singleton, K. J., \& Hansen, L. P. (1983). Stochastic Consumption, Risk Aversion, and the Tempoal Behavior of Asset Returns. The Journal of Political Economy, pp. 249-265.

Sturzenegger, F., \& Zettelmeyer, J. (2008). Haircuts: Estimating investor losses in sovereign debt restructurings, 1998-2005. Journal of International Money and Finance, pp. 780-805.

Tamura, K. (2002). The Problem of Sovereign Debt Restructuring: How Can We Deal with Holdout Problem Legally? Harvard Law School.

Tomz, M., \& Wright, M. L. (2007). Do countries default in "bad times". Journal of European Economic Association, pp. 352-360.

Wachter, J. (2001). Risk Aversion and Allocation to Long-Term Bonds. NYU Working Paper No. FIN-01-067.

Weinschelbaum, F., \& Wynne, J. (2005). Renegotiation; Collective action clauses and sovereign debt markets. Journal of International Economics, pp. 47-72.

Wissenschaftlicher Beirat, B. f. (2011, Januar). Bundesministerium für Wirtschaft und Technologie. Retrieved October 26, 2013, from http://www.bmwi.de/BMWi/Redaktion/PDF/Publikationen/Studien/gutachttextueberschuldung-staatsinsolvenz-in-der-eu-wissenschaftlicherbeirat,property $=$ pdf, bereich $=$ bmwi, sprache $=$ de, $r w b=$ true.pdf

Yeyati, E. L., \& Panizza, U. (2011). The elusive of sovereign defaults. Journal of Development Economics, pp. 95-105. 